\title{
Dyspnea, Eosinopenia, Consolidation, Acidemia and Atrial Fibrillation Score and BAP-65 Score, Tools for Prediction of Mortality in Acute Exacerbations of Chronic Obstructive Pulmonary Disease: A Comparative Pilot Study
}

\author{
Viral Sangwan, Dhruva Chaudhry, Roopa Malik ${ }^{1}$ \\ Departments of Pulmonary and Critical Care Medicine and ${ }^{1}$ Obstetrics and Gynaecology, PGIMS, Rohtak, Haryana, India
}

\section{Abstract}

Introduction: Acute exacerbations of chronic obstructive pulmonary disease (AECOPD) being common and often fatal, prognostic tools in AECOPD are lacking. Materials and Methods: A prospective, observational study was carried out in fifty patients of AECOPD admitted in A and E department. Dyspnea, Eosinopenia, Consolidation, Acidemia and atrial Fibrillation (DECAF) score and elevated blood urea nitrogen, altered mental status, pulse $>109$, age $>65$ (BAP-65) score were calculated. Dyspnea was scored using extended Medical Research Council Dyspnoea score. Data were collected and analyzed using SPSS 17.0 software. Results: Forty-one patients were discharged and 9 (18\%) died during treatment. Patients who were discharged and patients who died during hospital stay were compared. There was no significant difference in terms of sociodemographic variables, presence of comorbidities, and other markers of disease severity. A significant difference was found in blood counts, blood urea, serum creatinine, acidotic respiratory failure, and atrial fibrillation. A higher value of DECAF score and BAP-65 score was found more commonly in patients who died. Sensitivity for prediction of mortality for DECAF score and BAP-65 score was $100 \%$ and specificity was $34.1 \%$ and $63.4 \%$, respectively. Sensitivity for prediction of need for invasive ventilation for DECAF score and BAP-65 score was $80 \%$ and $100 \%$, respectively, and specificity was $80 \%$ and $60 \%$, respectively. Conclusion: Both DECAF and BAP-65 scores were found to be good predictors of mortality and need for ventilation in this pilot study.

Keywords: Acute exacerbation chronic obstructive pulmonary disease, mortality, ventilation

\section{INTRODUCTION}

Chronic obstructive pulmonary disease (COPD)-related deaths are now the fourth leading cause of death worldwide and it will become the third leading cause of death worldwide by $2020 .{ }^{[1-3]}$ The increasing mortality has been attributed to smoking epidemic and the advanced age of world population. COPD is defined as "a chronic slowly progressive disease characterized by airflow obstruction that does not change markedly over several months." Therefore, COPD is defined independent of exacerbations. Exacerbations are infrequent in early COPD and are largely a feature of moderate-to-severe disease. ${ }^{[4]}$ The American Thoracic Society and European Respiratory Society define COPD exacerbation as an acute change in patient's dyspnea, cough, or sputum that is beyond normal variability and that is sufficient to warrant a change in therapy. ${ }^{[5]}$

\begin{tabular}{|l|l|}
\hline \multicolumn{3}{|c|}{ Access this article online } \\
\hline Quick Response Code: & Website: \\
\hline & www.ijccm.org \\
\hline & \\
\hline
\end{tabular}

Despite exacerbations of COPD being both common and fatal, accurate prognostication of patients hospitalized with an exacerbation is difficult. In stable COPD, prognostic indices have been thoroughly investigated, and tools predicting mortality risk, such as BODE score, are well established. ${ }^{[6]}$ However, prognostic research in exacerbations requiring hospitalization has been limited, and there appears to be little common ground between predictors of mortality in stable disease and during acute exacerbation of COPD (AECOPD).

Address for correspondence: Dr. Viral Sangwan, House No. 1/9J, Medical Campus, Rohtak, Haryana, India. E-mail: drviralsangwan@yahoo.com

This is an open access article distributed under the terms of the Creative Commons Attribution-NonCommercial-ShareAlike 3.0 License, which allows others to remix, tweak, and build upon the work non-commercially, as long as the author is credited and the new creations are licensed under the identical terms.

For reprints contact: reprints@medknow.com

How to cite this article: Sangwan V, Chaudhry D, Malik R. Dyspnea, eosinopenia, consolidation, acidemia and atrial fibrillation score and BAP-65 score, tools for prediction of mortality in acute exacerbations of chronic obstructive pulmonary disease: A comparative pilot study. Indian J Crit Care Med 2017;21:671-7. 
A clinical mortality prediction tool in AECOPD could assist in decisions regarding the location of care, early escalation of care, appropriateness for end-of-life care, and suitability for early supported hospital discharge and therefore could help to reduce morbidity and mortality and direct the most efficient use of resources. In the present study, we studied and compared the recently added composite physiological score, i.e., Dyspnea, Eosinopenia, Consolidation, Acidemia and atrial Fibrillation (DECAF) score with the already existing elevated blood urea nitrogen (BUN), altered mental status, pulse $>109$, age $>65$ (BAP-65) score for prediction of mortality in patients admitted with AECOPD.

\section{Materials and Methods}

The present prospective, observational study was carried out on fifty consecutive patients of COPD with acute exacerbation admitted in emergency department. Patients with primary diagnosis of acute exacerbation of pulmonary disease, age $\geq 35$ years, and smoking history of $\geq 10$ cigarette pack-years were included in the study. Patients with previous inclusion in the study, on domiciliary ventilation, comorbidity expected to limit survival to $<12$ months (principally metastatic malignancy), and with primary reason for admission other than AECOPD were excluded from the study. After the initial evaluation, consisting of medical history, physical examination, 12-lead electrocardiography (ECG), arterial blood gas analysis, and standard laboratory tests, all patients underwent stable-state dyspnea scoring using the extended Medical Research Council Dyspnoea (eMRCD) score, DECAF score (eMRCD Va/Vb, eosinopenia $\left(<0.05 \times 10^{9} / \mathrm{L}\right)$, consolidation, academia ( $\mathrm{pH}<7.3)$, atrial fibrillation $[\mathrm{AF}]$ ), and BAP-65 score (BUN $>25$, altered mental status, pulse $>109 \mathrm{bpm}$, and age $>65$ years). eMRCD score subdivides patients too breathless to leave the house unaided (traditional MRCD 5) into those able independently to manage washing and/or dressing (eMRCD 5a) and those requiring assistance with both (eMRCD 5b). Details of comorbidity and maintenance medications were obtained from the patient. Presence of new consolidation on chest radiograph was recorded. Data were analyzed statistically.

\section{Statistical tests used}

Statistical testing was conducted with the Statistical Package for the Social Sciences version (SPSS, Chicago: SPSS Inc) 17.0. Continuous variables were presented as mean \pm standard deviation or median if the data were unevenly distributed. Categorical variables were expressed as frequencies and percentages. The comparison of normally distributed continuous variables between the groups was performed using Student's $t$-test. Nominal categorical data between the groups were compared using Chi-square test or Fisher's exact test as appropriate. Nonnormal distribution of continuous variables was made using Mann-Whitney U-test. A receiver operating characteristic (ROC) analysis was calculated to determine optimal cutoff value for total DECAF score and total BAP-65 score. The area under the curve, the sensitivity, and the specificity were also calculated to analyze the diagnostic value of total DECAF score and total BAP-65 score. For all statistical tests, $P<0.05$ was considered to indicate a significant difference.

\section{RESULTS}

A total of 63 patients of COPD were screened and fifty patients fulfilled the inclusion criteria. Out of 13 patients excluded from study, four patients were on domiciliary ventilation, one patient had metastatic malignancy, and eight patients were admitted for reason other than AECOPD. A total of fifty patients were included in the study. Out of these, 41 patients were discharged after treatment and nine patients died.

Sociodemographic data of patients are shown in Table 1. Out of the fifty patients included in the study, $43(86 \%)$ were male. Demographic differences of variables such as age, body mass index (BMI), and sex did not have any bearing on the study outcomes. No statistical difference was found between the patients who were discharged or who died $(P>0.05)$. Both the patients who were discharged and patients who died had similar interquartile range (IQR) in terms of smoking burden in pack-years $(P=0.835)$ and duration of illness $(P=0.502)$. There was no statistically significant difference between the number of hospital admission and number of acute exacerbations in previous year in the patients who were discharged or who died.

Clinical characteristics of patients are shown in Table 2. All patients had dyspnea as the chief presenting complaint. Thirty patients also had cough with sputum as the presenting complaint. Altered sensorium was present in 11 patients, out of these two patients died. There was statistically significant difference between patients who were discharged and who died in relation to cough with sputum as the presenting complaint $(P=0.007)$.

\begin{tabular}{|c|c|c|c|}
\hline Variable & $\begin{array}{l}\text { Survived to } \\
\text { discharge } \\
(n=41)\end{array}$ & $\begin{array}{c}\text { Died in } \\
\text { hospital } \\
(n=9)\end{array}$ & $P$ \\
\hline Age (years) (mean $\pm \mathrm{SD})$ & $61.20 \pm 8.42$ & $66.56 \pm 4.69$ & 0.072 \\
\hline BMI & $26.29 \pm 2.77$ & $26.33 \pm 1.73$ & 0.967 \\
\hline Sex (male/female) & $36 / 5$ & $7 / 2$ & 0.595 \\
\hline $\begin{array}{l}\text { Duration of illness (years), } \\
\text { median (IQR) }\end{array}$ & $10(8-11)$ & $10(9-11)$ & 0.502 \\
\hline $\begin{array}{l}\text { Smoking burden (pack-years), } \\
\text { median (IQR) }\end{array}$ & $30(20-40)$ & $30(22.50-40)$ & 0.835 \\
\hline \multicolumn{4}{|l|}{ Quality of life } \\
\hline Institutional care & 0 & 0 & - \\
\hline Living independently (\%) & $41(100)$ & $8(88.9)$ & 0.180 \\
\hline Housebound (\%) & $18(43.9)$ & $3(33.3)$ & 0.716 \\
\hline $\begin{array}{l}\text { Number of hospital admissions } \\
\text { in previous year, median (IQR) }\end{array}$ & $2.0(0-2)$ & $2.0(0.5-2.5)$ & 0.791 \\
\hline $\begin{array}{l}\text { Number of acute exacerbations } \\
\text { in previous year, median (IQR) }\end{array}$ & $2.0(0.5-2)$ & $2.0(1.0-2.5)$ & 0.480 \\
\hline
\end{tabular}




\begin{tabular}{|c|c|c|c|}
\hline & $\begin{array}{l}\text { Survived to } \\
\text { discharge } \\
(n=41)\end{array}$ & $\begin{array}{l}\text { Died in } \\
\text { hospital } \\
(n=9)\end{array}$ & $P$ \\
\hline \multicolumn{4}{|l|}{$\begin{array}{l}\text { Markers of disease } \\
\text { severity }(\%)\end{array}$} \\
\hline Long-term $\mathrm{O}_{2}$ therapy & 12.2 & 11.1 & 1.000 \\
\hline $\begin{array}{l}\text { Previous admissions } \\
\text { requiring NIV }\end{array}$ & 34.1 & 44.4 & 0.705 \\
\hline Cor pulmonale & 29.3 & 2.3 & 0.023 \\
\hline Long-term prednisolone & 46.3 & 66.7 & 0.463 \\
\hline Home-nebulized therapy & 58.5 & 55.6 & 1.000 \\
\hline \multicolumn{4}{|l|}{ Comorbidities (\%) } \\
\hline Cerebrovascular disease & 2.4 & 0 & 1.000 \\
\hline Ischemic heart disease & 2.4 & 0 & 1.000 \\
\hline Hypertension & 0 & 0 & - \\
\hline Diabetes & 0 & 0 & - \\
\hline $\begin{array}{l}\text { Left ventricular } \\
\text { dysfunction }\end{array}$ & 0 & 0 & - \\
\hline Chronic kidney disease & 0 & 0 & - \\
\hline \multicolumn{4}{|l|}{ Presenting complaints (\%) } \\
\hline Dyspnea & 100.0 & 100.0 & - \\
\hline Cough with sputum & 51.2 & 100.0 & 0.007 \\
\hline Altered sensorium & 22.0 & 22.2 & 1.000 \\
\hline Other & 7.3 & 0 & - \\
\hline \multicolumn{4}{|l|}{ Examination } \\
\hline \multicolumn{4}{|l|}{ Vitals (mean $\pm \mathrm{SD}$ ) } \\
\hline Pulse rate (bpm) & $97.10 \pm 12.85$ & $108.89 \pm 10.77$ & 0.014 \\
\hline $\begin{array}{l}\text { Systolic blood } \\
\text { pressure (mmHg) }\end{array}$ & $115.33 \pm 14.53$ & $118.61 \pm 13.24$ & 0.512 \\
\hline $\begin{array}{l}\text { Diastolic blood } \\
\text { pressure }(\mathrm{mmHg})\end{array}$ & $71.66 \pm 8.39$ & $70.42 \pm 11.37$ & 0.757 \\
\hline Respiratory rate (/min) & $25.41 \pm 2.29$ & $25.56 \pm 2.40$ & 0.869 \\
\hline \multicolumn{4}{|l|}{$\begin{array}{l}\text { General physical } \\
\text { examination (\%) }\end{array}$} \\
\hline Acute confusion & 26.8 & 44.4 & 0.423 \\
\hline Pallor & 0 & 0 & - \\
\hline Icterus & 0 & 0 & - \\
\hline Cyanosis & 4.9 & 11.1 & 0.456 \\
\hline Clubbing & 0 & 11.1 & 0.180 \\
\hline Pedal edema & 14.6 & 0 & 0.576 \\
\hline Raised JVP & 12.2 & 0 & 0.570 \\
\hline \multicolumn{4}{|l|}{$\begin{array}{l}\text { Respiratory system } \\
\text { examination (\%) }\end{array}$} \\
\hline Rhonchi & 80.5 & 100.0 & 0.423 \\
\hline Crepts & 34.1 & 66.7 & 0.130 \\
\hline Other & 34.1 & 11.1 & 0.387 \\
\hline \multicolumn{4}{|l|}{$\begin{array}{l}\text { Cardiovascular system } \\
\text { examination }(\%)\end{array}$} \\
\hline Normal & 97.6 & 100.0 & 1.000 \\
\hline P2 loud & 2.4 & 0.0 & \\
\hline \multicolumn{4}{|l|}{ Abdominal examination (\%) } \\
\hline Normal & 97.6 & 100.0 & 1.000 \\
\hline Tender hepatomegaly & 2.4 & 0.0 & \\
\hline $\begin{array}{l}\text { Central nervous system } \\
\text { examination }(\%)\end{array}$ & & & \\
\hline
\end{tabular}

\begin{tabular}{lccc}
\hline Table 2: Contd... & $\begin{array}{c}\text { Survived to } \\
\text { discharge } \\
(\boldsymbol{n = 4 1 )}\end{array}$ & $\begin{array}{c}\text { Died in } \\
\text { hospital } \\
(\boldsymbol{n = 9 )}\end{array}$ & $\boldsymbol{P}$ \\
\hline Altered sensorium & 7.3 & 11.1 & 0.404 \\
Confusion & 12.2 & 33.3 & \\
Drowsy & 2.4 & 0 & \\
Normal & 78.0 & 55.6 & \\
\hline NIV: Noninvasive ventilation; SD: Standard deviation; JVP: Jugular \\
venous pulse
\end{tabular}

In our study, there was no statistically significant difference between the presence of comorbidities and presence of other markers of disease severity in the patients who were discharged or died, except for cor pulmonale which was present in significantly more number of discharged patients than died patients $(P=0.023)$. Mean pulse rate of the discharged and died patients was $97.10 \pm 12.85$ and $108.89 \pm 10.77$, respectively $(P=0.014)$, which was statistically significant. We did not find any statistically significant difference in mean value of systolic blood pressure, diastolic blood pressure, respiratory rate, and temperature. No statistically significant difference was found between general physical examination and systemic examination of discharged and died patients in our study.

Investigations of patients are shown in Table 3. In the present study, statistically significant difference was found in the values of mean neutrophil count, lymphocyte count, eosinophil count and absolute eosinophil count, blood urea, and serum creatinine of discharged and died patients. Overall, a higher number of died patients had acidotic respiratory failure than that of discharged patients $(P=0.007)$. Consolidation on chest radiograph was seen in a significantly higher number of patients who died $(P=0.006)$. Nearly $33.3 \%$ of died patients had AF on ECG while none in the discharged group had AF.

Different types of ventilation required by patients are shown in Table 4. Out of all discharged patients, $26.8 \%, 65.9 \%$, and $7.3 \%$ required invasive, noninvasive, and no ventilation for the management of AECOPD, respectively, and all died patients required invasive mechanical ventilation (IMV) $(P<0.001)$.

Various mortality-predicting scores were calculated, as shown in Table 5. On DECAF scoring, significantly higher number of patients who died $(P=0.007)$ had Grade Va eMRCD score, eosinopenia $(P<0.001)$, consolidation lung $(P=0.007)$, and AF $(P=0.004)$. Acidemia alone was not significantly associated with mortality. On statistical analysis, higher value of DECAF score was significantly found more commonly in patients who died during the study period $(P<0.001)$.

On BAP-65 scoring, all components of BAP-65 score were found more commonly associated with mortality and the difference was found to be statistically significant also. 


\begin{tabular}{|c|c|c|c|}
\hline Variable & Survived to discharge $(n=41)$ & Died in hospital $(n=9)$ & $P$ \\
\hline \multicolumn{4}{|l|}{ Biochemical parameters (mean \pm SD) } \\
\hline $\mathrm{Hb}(\mathrm{g} \%)$ & $12.78 \pm 2.33$ & $13.67 \pm 1.03$ & 0.087 \\
\hline $\mathrm{TLC} / \mathrm{mm}^{3}$ & $12,451.22 \pm 5207.02$ & $13,144.44 \pm 2903.06$ & 0.702 \\
\hline Neutrophils & $83.56 \pm 6.15$ & $88.78 \pm 2.54$ & $<0.001$ \\
\hline Lymphocytes & $12.39 \pm 5.55$ & $8.78 \pm 1.72$ & 0.001 \\
\hline Monocytes & $1.73 \pm 0.77$ & $1.22 \pm 0.44$ & 0.064 \\
\hline Eosinophils & $1.95 \pm 0.59$ & $1.22 \pm 0.44$ & 0.001 \\
\hline Absolute eosinophil count & $165 \pm 66.61$ & $71.11 \pm 61.73$ & $<0.001$ \\
\hline Platelet count (lakh/mm $\left.\mathrm{mm}^{3}\right)$ & $1.63 \pm 0.59$ & $1.35 \pm 0.33$ & 0.184 \\
\hline Blood urea (mg\%) & $48.20 \pm 27.74$ & $111.67 \pm 59.50$ & 0.013 \\
\hline Fasting blood sugar $(\mathrm{mg} \%)$ & $94.29 \pm 17.27$ & $89.11 \pm 15.08$ & 0.410 \\
\hline Postprandial blood sugar (mg\%) & $140.29 \pm 22.70$ & $147.89 \pm 21.10$ & 0.363 \\
\hline Serum $\mathrm{Na}^{+}(\mathrm{mEq} / \mathrm{L})$ & $142.34 \pm 6.04$ & $143.00 \pm 5.98$ & 0.768 \\
\hline Serum $\mathrm{K}^{+}(\mathrm{mEq} / \mathrm{l})$ & $4.86 \pm 4.72$ & $3.90 \pm 0.42$ & 0.548 \\
\hline Serum creatinine $(\mathrm{mg} \%)$ & $0.91 \pm 0.27$ & $2.19 \pm 1.38$ & 0.024 \\
\hline Serum protein $(\mathrm{g} \%)$ & $6.66 \pm 0.64$ & $6.91 \pm 0.29$ & 0.076 \\
\hline Albumin: globulin ratio & $1.14 \pm 0.15$ & $1.16 \pm 0.14$ & 0.796 \\
\hline \multicolumn{4}{|l|}{ Blood gas analysis $($ mean \pm SD) } \\
\hline $\mathrm{pH}$ & $7.26 \pm 0.08$ & $7.18 \pm 0.03$ & 0.007 \\
\hline $\mathrm{pO}_{2}$ & $47.26 \pm 17.90$ & $51.10 \pm 13.93$ & 0.549 \\
\hline $\mathrm{pCO}_{2}$ & $78.73 \pm 20.66$ & $101.36 \pm 19.25$ & 0.004 \\
\hline $\mathrm{HCO}_{3}$ & $33.67 \pm 9.30$ & $29.61 \pm 5.14$ & 0.214 \\
\hline $\mathrm{O}_{2}$ saturation $(\%)$ & $72.83 \pm 23.76$ & $77.72 \pm 20.12$ & 0.569 \\
\hline \multicolumn{4}{|l|}{ Chest radiograph (\%) } \\
\hline Consolidation & 34.1 & 88.9 & 0.006 \\
\hline \multicolumn{4}{|l|}{ Electrocardiograph (\%) } \\
\hline Atrial fibrillation & 0 & 33.3 & 0.004 \\
\hline
\end{tabular}

TLC: Total leukocyte count; Hb: Hemoglobin; SD: Standard deviation

\begin{tabular}{|c|c|c|c|}
\hline Variable & $\begin{array}{c}\text { Survived to } \\
\text { discharge }(n=41)\end{array}$ & $\begin{array}{l}\text { Died in hospital } \\
\qquad(n=9)\end{array}$ & $P$ \\
\hline \multicolumn{4}{|c|}{ Type of ventilation (\%) } \\
\hline IMV & 26.8 & 100 & $<0.001$ \\
\hline NIV & 65.9 & 0 & \\
\hline NO & 7.3 & 0 & \\
\hline
\end{tabular}

NIV: Noninvasive ventilation; IMV: Invasive mechanical ventilation; NO: No ventilation required

Statistically significant higher values of BAP-65 scores were observed in patients who died $(P<0.001)$.

In our cohort, both DECAF score and BAP-65 score performed equally well for prediction of in-hospital mortality. The AUROC for prediction of mortality [Figure 1] for DECAF score was 0.905 (95\% confidence interval $[\mathrm{CI}]=0.791-1.000)$ and for BAP-65 score was 0.915 (95\% CI =0.828-1.001). Sensitivity for prediction of mortality for both DECAF and BAP-65 scores was $100 \%$ and specificity was $34.1 \%$ and $63.4 \%$, respectively. The AUROC for need for MV [Figure 2] was $0.881(95 \% \mathrm{CI}=0.790-0.972)$ for DECAF score and $0.797(95 \% \mathrm{CI}=0.665-0.928)$ for BAP-65 score.

\section{DISCUSSION}

AECOPD is a common cause of admission to Intensive Care Units (ICUs), but appropriate level of treatment of patients presenting to ICU with AECOPD is still debatable. Identifying upon admission those at high risk of dying in hospital could be useful for triaging patients to the appropriate level of care, determining aggressiveness of therapies, and guiding goals of care and safe discharges. There is an argument that whether ICU admission and invasive ventilation should be the default for all COPD patients presenting with acute respiratory failure or it should be offered as a last resort. Uncertainty as to whether to consider invasive ventilation in COPD patients is in part driven by an individual clinician's ability to confidently decide whether the intubation of patients with AECOPD is appropriate and which prognostic variables are predictive of poor outcome after ICU admission. ${ }^{[7,8]}$ A number of clinical variables exist that may be of prognostic significance in the management of COPD patients with acute exacerbation. Potential prognostic variables include age, smoking burden, premorbid factors, FEV1, exercise capacity, previous ICU admissions including severe exacerbations, prior functional status, BMI, requirement for $\mathrm{O}_{2}$ when stable, comorbidities, and various physiological and laboratory parameters and biomarkers. ${ }^{[9-16]}$ Given the systemic consequences of COPD, use of a composite index 


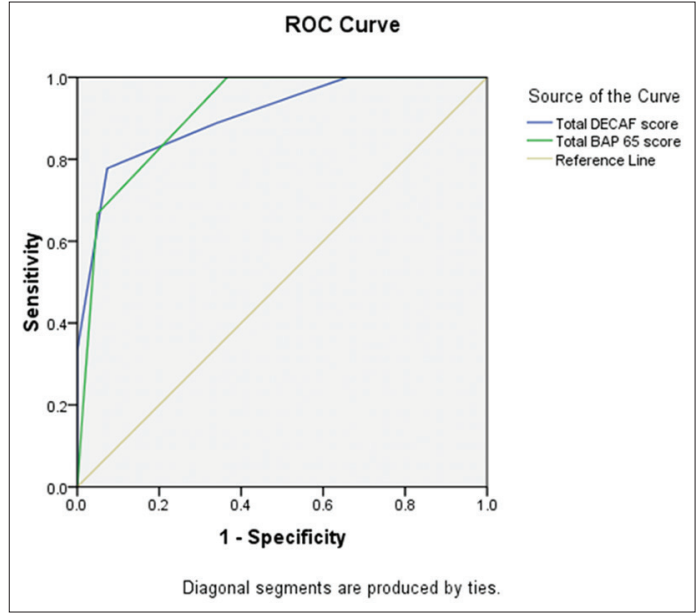

Figure 1: Receiver operator characteristic curve for mortality

\begin{tabular}{|c|c|c|c|}
\hline Variable & $\begin{array}{c}\text { Survived to } \\
\text { discharge } \\
(n=41), n(\%)\end{array}$ & $\begin{array}{l}\text { Died in hospital } \\
(n=9), n(\%)\end{array}$ & $P$ \\
\hline \multicolumn{4}{|l|}{ eMRCD score } \\
\hline I-IV & $16(39)$ & 0 & 0.103 \\
\hline Va & $23(56.1)$ & $9(100)$ & \\
\hline $\mathrm{Vb}$ & $2(4.9)$ & 0 & \\
\hline \multicolumn{4}{|l|}{ DECAF score } \\
\hline eMRCD Va & $23(56.1)$ & $9(100)$ & 0.007 \\
\hline eMRCD Vb & $2(4.9)$ & $0(0)$ & 1.000 \\
\hline $\begin{array}{l}\text { Eosinopenia } \\
\left(<0.05 \times 10^{9} / \mathrm{L}\right)\end{array}$ & $5(12.2)$ & $7(77.8)$ & $<0.001$ \\
\hline Consolidation & $14(34.1)$ & $8(89.9)$ & 0.007 \\
\hline $\begin{array}{l}\text { Acedemia } \\
(\mathrm{pH}<7.3)\end{array}$ & $38(92.7)$ & $9(100)$ & 1.000 \\
\hline $\begin{array}{l}\text { Atrial } \\
\text { fibrillation }\end{array}$ & 0 & $3(33)$ & 0.004 \\
\hline Median (IQR) & $2.0(1-3)$ & $4.0(3.5-5)$ & $<0.001$ \\
\hline \multicolumn{4}{|l|}{ BAP-65 score } \\
\hline $\mathrm{BUN}>25$ & $19(46.3)$ & $9(100)$ & 0.003 \\
\hline $\begin{array}{l}\text { Altered } \\
\text { mental status }\end{array}$ & $13(31.7)$ & $3(33.3)$ & 1.000 \\
\hline $\begin{array}{l}\text { Pulse } \\
>109 \mathrm{bpm}\end{array}$ & $10(24.4)$ & $6(66.7)$ & 0.022 \\
\hline Age $>65$ years & $11(26.8)$ & $7(77.8)$ & 0.007 \\
\hline Median (IQR) & $1.0(1.0-2.0)$ & $3.0(2.0-3.0)$ & $<0.001$ \\
\hline
\end{tabular}

BUN: Blood urea nitrogen; eMRCD: Extended Medical Research Council Dyspnoea; DECAF: Dyspnea, Eosinopenia, Consolidation, Acidemia and atrial Fibrillation; IQR: Interquartile range; BAP-65: Elevated blood urea nitrogen, altered mental status, pulse $>109$, age $>65$

to assess prognosis may provide a more comprehensive way to evaluate COPD. Of these, clinical physiological markers, incorporated into the BODE index and other multidimensional staging tools, may be valuable in the assessment of severity and progression of disease. BODE index is the primarily established tool for prediction of mortality in stable COPD

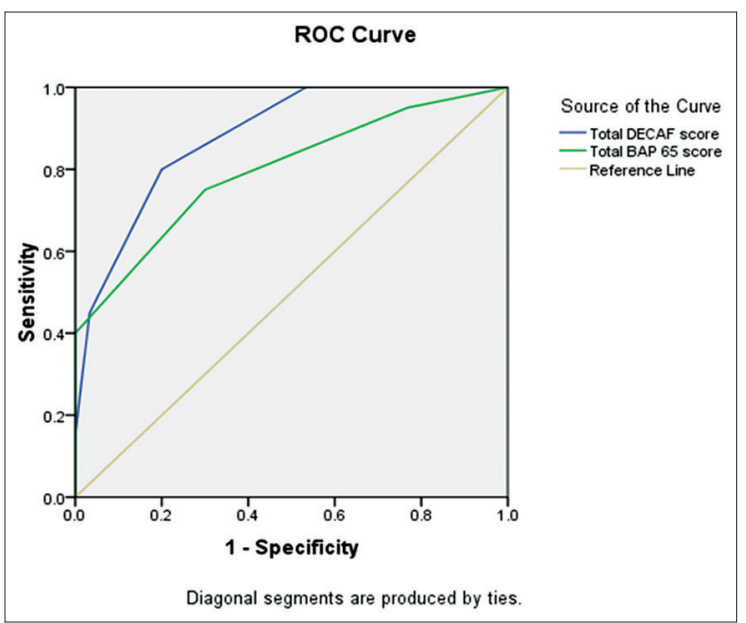

Figure 2: Receiver operator characteristic curve for need for mechanical ventilation

patients. ${ }^{[6]}$ Several tools have been proposed for prediction of mortality in AECOPD such as CURB-65, BAP-65 score, and DECAF score. ${ }^{[17-19]}$ The use of CURB-65 score for assessment and guidance of therapy in patients hospitalized with AECOPD complicated with consolidation has been shown to be suboptimal. ${ }^{[19]}$ DECAF score has been added very recently to the tools but lacks external validation. According to study by Steer et al., DECAF score is a stronger prognostic score than CURB-65, APACHE, or COPD and Asthma Physiological Score predictive tools. ${ }^{[19]}$ We evaluated the use of DECAF score for prediction of mortality in patients admitted to our ICU with AECOPD and also compared DECAF score with already existing BAP-65 score.

A total of 63 patients were analyzed, fifty patients fulfilled the inclusion criteria, and were analyzed in the study. Forty-one patients were discharged after treatment and $9(18 \%)$ patients died during hospital stay. In the study by Steer et al. and Shorr et al., mortality among patients with AECOPD was $10.4 \%$ and $4 \%$, respectively, possibly reflecting the different threshold for hospital admission among different countries. ${ }^{[17,19]}$

In our study, $33.3 \%$ of died patients had AF while none in the discharged group had AF. Changes in blood gases, abnormalities in pulmonary functions, and hemodynamic changes resulting from AECOPD can lead to the development of AF. AF and COPD frequently coexist and complicate treatment of both conditions. The treatment of COPD exacerbation may include beta-adrenergic agonist and theophylline, which can precipitate AF with rapid ventricular response. Pharmacologic and electrical cardioversion may be ineffective in the management of AF in patients with COPD until respiratory decompensation has been corrected, hence associated with increased mortality as is evident in our study.

Dyspnea of all patients was scored using eMRCD score. Out of the total 50 AECOPD patients studied, 32 patients had eMRCD score of Va. All died patients (9) had eMRCD score of Va. No significant relationship was found in eMRCD 
scores of discharged and died patients $(P=0.103)$. Our results are contrary to those seen in study by Steer et al ${ }^{[19]}$ They found a significant correlation $(P<0.001)$ between median eMRCD scores of patients who survived and died, $4(3-5 a)$ and 5 (5a and b), respectively. The reason of this difference may be due to small sample size in our study and difference in perception of levels of activity causing dyspnea, therefore altering the dyspnea score.

In our study, when individual components of DECAF score were compared between survivors and died patients, statistically significant difference was found in eMRCD Va $(56.1 \%$ vs. $100 \%$, $P=0.007)$, eosinopenia $<0.05 \times 10^{9} \mathrm{~L}(12.2 \%$ vs. $77.8 \%$, $P<0.001$ ), consolidation ( $34.1 \%$ and $89.9 \%, P=0.007$ ), and AF (0 vs. $33.3 \%, P=0.004)$. Comparison of eMRCD Vb and academia $\mathrm{pH}<7.3$ was not found to be significant. In our study, due to small sample size, only two patients had eMRCD $\mathrm{Vb}$ score. When total DECAF score was considered, with rising DECAF score, there was rise in mortality $(P<0.001)$. Significant correlation was found on comparison of median and IQR for DECAF score between survivors and died patients $(2.0[1-3]$ vs. 4.0 [3.5-5.0], $P<0.001)$. The area under DECAF score (ROC curve) for prediction of mortality [Figure 1 and Table 6] was 0.905 (95\% CI: 0.791-1.000), indicating good validity. The sensitivity, specificity, positive predictive value, negative predictive value, $P$ value, and accuracy in prediction of mortality by DECAF score were $100 \%$, $34.1 \%, 25 \%, 100 \%, 0.047$, and $46 \%$, respectively [Table 6].

Steer et al. in their study found that each individual component of DECAF score was an independent categorical predictor of mortality, eMRCD Va (odds ratio $[\mathrm{OR}]=5.11[95 \% \mathrm{CI}: 2.62-9.97], P<0.001$ ), eMRCD Vb (OR $=7.30$ [95\% CI: 3.77-14.2], $P<0.001)$, consolidation $(\mathrm{OR}=2.88$ [95\% CI: 1.69-4.90], $P<0.001)$, eosinopenia (OR $=2.76$ [95\% CI: 1.58-4.83], $P<0.001$ ), $\mathrm{pH}(\mathrm{OR}=2.68$ [95\% CI: 1.41-5.09], $P=0.003)$, and presence of $\mathrm{AF}(\mathrm{OR}=2.66$ [95\% CI: $1.39-5.09], P=0.003)$. The area under ROC curve for predicting in-hospital mortality was 0.86 (95\% CI: 0.82-0.89), indicating good validity. ${ }^{[19]}$ In the present study, area under DECAF score (ROC curve) for prediction of need for invasive ventilation [Figure 2 and Table 7] was 0.881 (95\% CI: $0.790-0.972)$, indicating good validity. The sensitivity, specificity, positive predictive value, negative predictive value, $P$ value, and accuracy of DECAF score in prediction of need for invasive ventilation were $80 \%$, $80 \%, 72.7 \%, 85.7 \%,<0.001$, and $80 \%$, respectively, in our study [Table 7].

In our study, when individual components of BAP-65 score were compared between survivors and died patients, statistically significant difference was found in BUN $>25$ ( $46 \%$ vs. $100 \%$, $P=0.003)$, pulse $>109 \mathrm{bpm}(24.4 \%$ vs. $66.7 \%, P=0.022)$, and age $>65$ years $(26.8 \%$ and $77.8 \%, P=0.007)$. Comparison of altered mental status was not found to be significant. When total BAP-65 score was considered, with rising BAP-65 score, there was rise in mortality $(P<0.001)$. Significant correlation

\begin{tabular}{|c|c|c|}
\hline & DECAF score & BAP-65 score \\
\hline AUC $(95 \% \mathrm{CI})$ & $0.905(0.791-1.000)$ & $0.915(0.828-1.001)$ \\
\hline Sensitivity (\%) & 100 & 100 \\
\hline Specificity (\%) & 34.10 & 63.4 \\
\hline PPV (\%) & 25 & 37.5 \\
\hline NPV (\%) & 100 & 100 \\
\hline$P$ & 0.047 & 0.001 \\
\hline Accuracy (\%) & 46 & 50 \\
\hline
\end{tabular}

AUC: Area under the curve; CI: Confidence interval; PPV: Positive predictive value; NPV: Negative predictive value; DECAF: Dyspnea, Eosinopenia, Consolidation, Acidemia and atrial Fibrillation; BAP-65: Elevated blood urea nitrogen, altered mental status, pulse $>109$, age $>65$

Table 7: Results of Dyspnea, Eosinopenia, Consolidation, Acidemia and atrial Fibrillation score and elevated blood urea nitrogen, altered mental status, pulse $>109$, age $>65$ score for prediction of need for mechanical ventilation

\begin{tabular}{lcc}
\hline & DECAF score & BAP-65 score \\
\hline AUC (95\% CI) & $0.881(0.790-0.972)$ & $0.797(0.665-0.928)$ \\
Sensitivity (\%) & 80 & 100 \\
Specificity (\%) & 80 & 60 \\
PPV (\%) & 72.7 & 35 \\
NPV (\%) & 85.7 & 100 \\
$P$ & $<0.001$ & 0.001 \\
Accuracy (\%) & 80 & 50 \\
\hline AUC: Area under the curve; CI: Confidence interval; PPV: Positive \\
predictive value; NPV: Negative predictive value; DECAF: Dyspnea, \\
Eosinopenia, Consolidation, Acidemia and atrial Fibrillation; BAP-65: \\
Elevated blood urea nitrogen, altered mental status, pulse >109, age >65
\end{tabular}

was found on comparison of median and IQR for BAP-65 score between survivors and died patients $(1.0[1.0-2.0]$ vs. $3.0[2.0-3.0], P<0.001)$.

The area under BAP-65 score (ROC curve) for prediction of mortality [Figure 1 and Table 6] was $0.915(95 \%$ CI: $0.828-1.001)$, indicating good validity. The sensitivity, specificity, positive predictive value, negative predictive value, $P$ value, and accuracy in prediction of mortality by BAP-65 score were $100 \%, 63.4 \%, 37.5 \%, 100 \%, 0.001$, and $50 \%$, respectively [Table 6]. In the present study, area under BAP-65 score (ROC curve) for prediction of need for invasive ventilation [Figure 2 and Table 7] was 0.797 (95\% CI: $0.665-0.928$ ), indicating good validity. The sensitivity, specificity, positive predictive value, negative predictive value, $P$ value, and accuracy of BAP-65 score in prediction of need for invasive ventilation were $100 \%, 60 \%, 35 \%, 100 \%, 0.001$, and $50 \%$, respectively [Table 7 ].

In the study by Shorr et al. for prediction of mortality and need for IMV, the area under the ROC curve for BAP-65 score was 0.77 (95\% CI: $0.76-0.78)$ and 0.78 (95\% CI: 0.78-0.79), 
respectively. For the pooled mortality and MV need as end point, the cutoff point of class $>\mathrm{II},>\mathrm{III},>\mathrm{IV}$, or $\mathrm{V}$ corresponded to sensitivity ranging from 0.97 to 0.12 , specificity ranging from 0.18 to 0.99 , a positive predictive value ranging from 0.13 to 0.64 , and a negative predictive value ranging from 0.98 to 0.90 , respectively. ${ }^{[17]}$

On comparison of DECAF score and BAP-65 score for prediction of mortality and need for MV in AECOPD patients, on Pearson's correlation graph [Figure 3], we found a significant correlation $(r=0.602, P<0.001)$. The correlation between DECAF score and BAP-65 was found to be linear. Although we had a small sample size in our study, if these two simple scores are well validated by larger studies, either of them can be used on the bed side of the patient to guide clinical care.

\section{Conclusion}

To conclude, a clinical prediction tool must have practicality, validity, and utility. Both scores are practical in the sense that both can be calculated easily using simple questions and routine laboratory investigations. Both DECAF and BAP-65 scores were found to be good predictors of mortality and need for IMV in the present study, in spite of small number. Larger studies are required for validation of these two simple tools to use them routinely in clinical judgment and triage of patients, i.e., to decide which patients should be given ventilator support or deferred from MV. However, individualization must be done based on clinical judgment and family goals.

\section{Financial support and sponsorship}

Nil.

\section{Conflicts of interest}

There are no conflicts of interest.

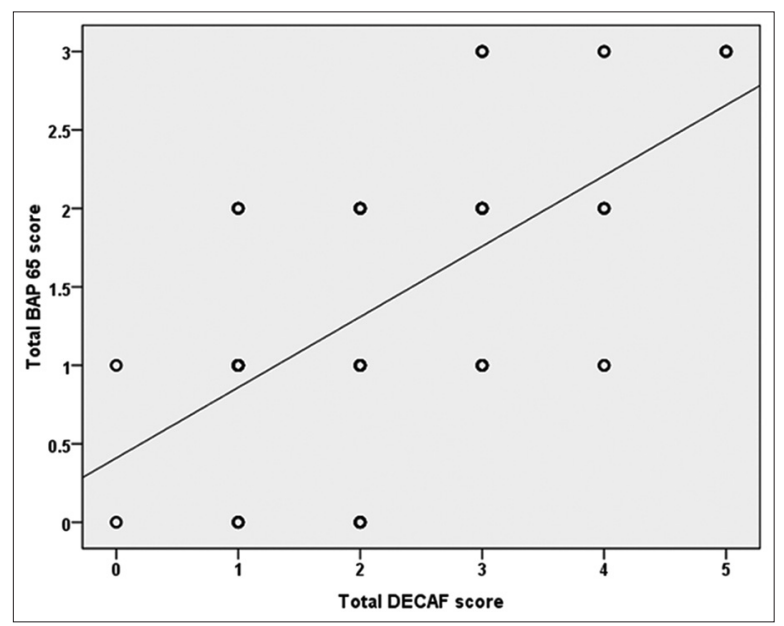

Figure 3: Pearson's (linear correlation) graph between elevated blood urea nitrogen, altered mental status, pulse $>109$, age $>65$ score and Dyspnea, Eosinopenia, Consolidation, Acidemia and atrial Fibrillation score

\section{References}

1. World Health Organization. Available from: http:/www.who.int/ rsXespiratory/copd/burden/en/index.html.

2. Murray CJ, Lopez AD. Global mortality, disability, and the contribution of risk factors: Global burden of disease study. Lancet 1997;349:1436-42.

3. Rabe KF, Hurd S, Anzueto A, Barnes PJ, Buist SA, Calverley P, et al. Global strategy for the diagnosis, management, and prevention of chronic obstructive pulmonary disease: GOLD executive summary. Am J Respir Crit Care Med 2007;176:532-55.

4. BTS guidelines for the management of chronic obstructive pulmonary disease. The COPD Guidelines Group of the Standards of Care Committee of the BTS. Thorax 1997;52 Suppl 5:S1-28.

5. Celli BR, MacNee W, ATS/ERS Task Force. Standards for the diagnosis and treatment of patients with COPD: A summary of the ATS/ERS position paper. Eur Respir J 2004;23:932-46.

6. Celli BR, Cote CG, Marin JM, Casanova C, Montes de Oca M, Mendez RA, et al. The body-mass index, airflow obstruction, dyspnea, and exercise capacity index in chronic obstructive pulmonary disease. N Engl J Med 2004;350:1005-12.

7. Kostopoulou O, Wildman M. Sources of variability in uncertain medical decisions in the ICU: A process tracing study. Qual Saf Health Care 2004;13:272-80.

8. Wildman MJ, O’Dea J, Kostopoulou O, Tindall M, Walia S, Khan Z, et al. Variation in intubation decisions for patients with chronic obstructive pulmonary disease in one critical care network. QJM 2003;96:583-91.

9. Martínez-García MA, de la Rosa Carrillo D, Soler-Cataluña JJ, Donat-Sanz Y, Serra PC, Lerma MA, et al. Prognostic value of bronchiectasis in patients with moderate-to-severe chronic obstructive pulmonary disease. Am J Respir Crit Care Med 2013;187:823-31.

10. Moreno A, Montón C, Belmonte Y, Gallego M, Pomares X, Real J, et al. Causes of death and risk factors for mortality in patients with severe chronic obstructive pulmonary disease. Arch Bronconeumol 2009;45:181-6.

11. Tantucci C, Donati P, Nicosia F, Bertella E, Redolfi S, De Vecchi M, et al. Inspiratory capacity predicts mortality in patients with chronic obstructive pulmonary disease. Respir Med 2008;102:613-9.

12. Casanova C, Cote C, de Torres JP, Aguirre-Jaime A, Marin JM, Pinto-Plata V, et al. Inspiratory-to-total lung capacity ratio predicts mortality in patients with chronic obstructive pulmonary disease. Am J Respir Crit Care Med 2005;171:591-7.

13. Slenter RH, Sprooten RT, Kotz D, Wesseling G, Wouters EF, Rohde GG, et al. Predictors of 1-year mortality at hospital admission for acute exacerbations of chronic obstructive pulmonary disease. Respiration 2013;85:15-26.

14. Steer J, Norman EM, Afolabi OA, Gibson GJ, Bourke SC. Dyspnoea severity and pneumonia as predictors of in-hospital mortality and early readmission in acute exacerbations of COPD. Thorax 2012;67:117-21.

15. Soler-Cataluña JJ, Martínez-García MA, Sánchez LS, Tordera MP, Sánchez PR. Severe exacerbations and BODE index: Two independent risk factors for death in male COPD patients. Respir Med 2009;103:692-9.

16. Barnes PJ, Chowdhury B, Kharitonov SA, Magnussen H, Page CP, Postma D, et al. Pulmonary biomarkers in chronic obstructive pulmonary disease. Am J Respir Crit Care Med 2006;174:6-14.

17. Shorr AF, Sun X, Johannes RS, Yaitanes A, Tabak YP. Validation of a novel risk score for severity of illness in acute exacerbations of COPD. Chest 2011;140:1177-83.

18. Shorr AF, Sun X, Johannes RS, Derby KG, Tabak YP. Predicting the need for mechanical ventilation in acute exacerbations of chronic obstructive pulmonary disease: Comparing the CURB-65 and BAP-65 scores. J Crit Care 2012;27:564-70.

19. Steer J, Gibson J, Bourke SC. The DECAF score: Predicting hospital mortality in exacerbations of chronic obstructive pulmonary disease. Thorax 2012;67:970-6. 